\title{
Iron-catalyzed Suzuki-Miyaura Coupling Reaction of Unactivated Alkyl Halides with Lithium Alkynylborates
}

\author{
Naohisa Nakagawa, ${ }^{1,2}$ Takuji Hatakeyama, ${ }^{1,3, \dagger}$ and Masaharu Nakamura*1,2 \\ ${ }^{1}$ International Research Center for Elements Science (IRCELS), Institute for Chemical Research (ICR), \\ Kyoto University, Uji, Kyoto 611-0011 \\ ${ }^{2}$ Department of Energy and Hydrocarbon Chemistry, Graduate School of Engineering, \\ Kyoto University, Nishikyo-ku, Kyoto 615-8510 \\ ${ }^{3}$ Elements Strategy Initiative for Catalysts and Batteries (ESICB), Kyoto University, Nishikyo-ku, Kyoto 615-8520
}

(E-mail: masaharu@scl.kyoto-u.ac.jp)

A Suzuki-Miyaura coupling reaction between unactivated alkyl halides and lithium alkynylborates was performed using an iron-bisphosphine catalyst. The reaction shows high chemoselectivity and is applicable to a broad scope of substrates bearing electrophilic functional groups. A radical probe experiment using cyclopropylmethyl bromide was conducted to investigate the nature of the intermediate in the reaction, showing that an alkyl radical species is generated from the alkyl halide substrate.

The Suzuki-Miyaura coupling reaction has been widely used for the synthesis of functional organic molecules, such as pharmaceuticals, agrochemicals, and electronic materials. ${ }^{1}$ In particular, the Suzuki-Miyaura coupling of alkynyl borate reagents has become recognized as a powerful tool for installing a $\mathrm{C}-\mathrm{C}$ triple bond moiety without altering other reactive functional groups on the substrates. ${ }^{2}$ Since Soderquist and Fürstner independently reported the palladium-catalyzed alkynylation between alkynyl borate reagents and aryl or alkenyl halides, ${ }^{2 b, 2 \mathrm{c}}$ the reaction has been successfully applied as a key step in the synthesis of natural products. ${ }^{3}$ However, while aryl and alkenyl halides have been widely employed in this alkynylation reaction, the use of unactivated alkyl halides has remained challenging due to their reluctance to oxidative addition and the competing nonproductive $\beta$-hydrogen elimination from the alkyl-metal intermediate. Consequently, there has been no report on the use of alkynylborates in $\mathrm{C}_{\mathrm{sp}}-\mathrm{C}_{\mathrm{sp}}{ }^{3}$ bond-forming reactions with unactivated alkyl halides, despite extensive studies using various combinations of alkynyl donors and transition-metal catalysts such as palladium, ${ }^{4 a, 4 b, 5 a}$ nickel, ${ }^{4 \mathrm{c}, 4 \mathrm{~d}, 5 \mathrm{~b}}$ cobalt, ${ }^{5 \mathrm{c}-5 \mathrm{f}}$ and iron. ${ }^{5 \mathrm{~g}, 5 \mathrm{~h}}$

We have previously reported a Sonogashira-type coupling between alkyl halides and alkynyl Grignard reagents with the iron-bisphosphine catalyst $\left[\mathrm{FeCl}_{2}(\mathrm{SciOPP})\right]^{5 \mathrm{~g}, 6}$ (Scheme $\left.1 \mathrm{~A}\right)$. Although this reaction demonstrated the potential of the iron catalyst in the alkynylation of alkyl halides, significant synthetic limitations have remained, i.e., low functional group compatibility, the inapplicability of the reaction to secondary alkyl chlorides, and the need for overly elaborate protocols such as the slow addition of Grignard reagents at refluxing temperature. Herein we present the first example of Suzuki-Miyaura coupling between alkynylborates and unactivated alkyl halides in the presence of an iron catalyst, ${ }^{7,8}$ which overcomes these limitations to provide a facile route to alkyl-substituted functionalized alkynes in good to excellent yields (Scheme 1B).

We began our investigation by evaluating the coupling reaction of chlorocycloheptane (1) and lithium (triisopropyl-
(A) Previous work: Iron-catalyzed Sonogashira-type coupling of alkyl halides

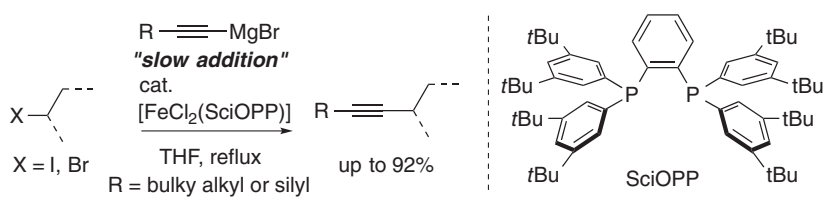

(B) This work: Iron-catalyzed Suzuki-Miyaura coupling of alkyl halides

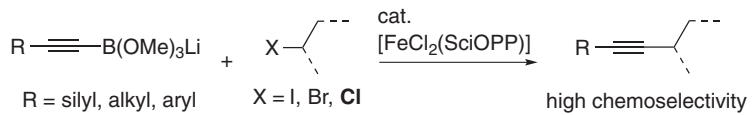

Scheme 1. Iron-bisphosphine-catalyzed $\mathrm{C}_{\mathrm{sp}}-\mathrm{C}_{\mathrm{sp}^{3}}$ bond-forming reaction of unactivated alkyl halides.

Table 1. Effect of reaction parameters on iron-catalyzed alkynylation Optimal condition
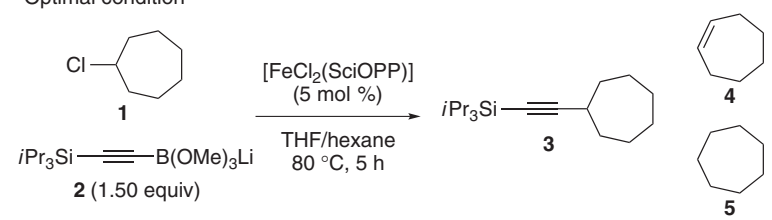

\begin{tabular}{|c|c|c|c|c|c|}
\hline \multirow{2}{*}{ Entry $^{\mathrm{a}}$} & \multirow{2}{*}{ Variations from the optimal conditions } & \multicolumn{3}{|c|}{ Yield $/ \%^{b}$} & \multirow{2}{*}{$\begin{array}{l}\text { Recovery } \\
\text { of } 1 / \%\end{array}$} \\
\hline & & 3 & 4 & 5 & \\
\hline 1 & none & 80 & 16 & 3 & $<1$ \\
\hline 2 & without $\left[\mathrm{FeCl}_{2}(\mathrm{SciOPP})\right]$ & 0 & 0 & 0 & $>99$ \\
\hline 3 & $5 \mathrm{~mol} \%$ of $\mathrm{FeCl}_{2}{ }^{\mathrm{c}}$ & 10 & 4 & 5 & 74 \\
\hline 4 & $5 \mathrm{~mol} \%$ of $\left[\mathrm{FeCl}_{2}(\mathrm{dppbz})_{2}\right]$ & 0 & 0 & 0 & $>99$ \\
\hline 5 & $5 \mathrm{~mol} \%$ of $\mathrm{FeCl}_{2}$ and $\mathrm{DPPE}^{\mathrm{c}}$ & $<1$ & $<1$ & $<1$ & 94 \\
\hline 6 & $5 \mathrm{~mol} \%$ of $\mathrm{FeCl}_{2}{ }^{\mathrm{d}}$ with NMP $(2 \mathrm{~mL})$ & 8 & 5 & 1 & 63 \\
\hline 7 & $\mathrm{~B}(\mathrm{O} i \mathrm{Pr})_{3}$ instead of $\mathrm{B}(\mathrm{OMe})_{3}$ in 2 & 0 & 1 & 1 & 97 \\
\hline 8 & 9-MeO-9-BBN instead of $\mathrm{B}(\mathrm{OMe})_{3}$ in 2 & 0 & $<1$ & $<1$ & 94 \\
\hline
\end{tabular}

${ }^{\mathrm{a}}$ Reactions were carried out at the $0.50 \mathrm{mmol}$ scale. ${ }^{\mathrm{b}}$ Yields were determined by quantitative $\mathrm{GC}$ analyses using dodecane as an internal standard. ${ }^{\mathrm{c}} \mathrm{FeCl}_{2}$ (thf) $)_{1.5}$ was used. ${ }^{\mathrm{d}}$ Anhydrous $\mathrm{FeCl}_{2}$ was used.

silyl)ethynyltrimethoxoborate (2), ${ }^{9}$ readily prepared from the terminal alkyne, BuLi, and trimethyl borate, and found that by using $5 \mathrm{~mol} \%$ of $\left[\mathrm{FeCl}_{2}(\mathrm{SciOPP})\right]$ the target coupling product 3 was obtained in $80 \%$ yield, along with cycloheptene (4) and cycloheptane (5) (Table 1, Entry 1). Further investigation into the reaction conditions was conducted by altering individual reaction parameters from those considered to be optimal. ${ }^{10}$ In the absence of the iron catalyst, $\mathbf{1}$ was recovered quantitatively and no other products were observed (Table 1, Entry 2). Without the SciOPP ligand, the coupling reaction gave $\mathbf{3}$ in only $10 \%$ 
Table 2. Scope of substrates in iron-catalyzed Suzuki-Miyaura coupling with lithium alkynylborates ${ }^{\mathrm{a}}$

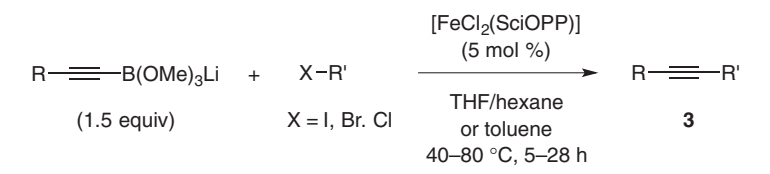

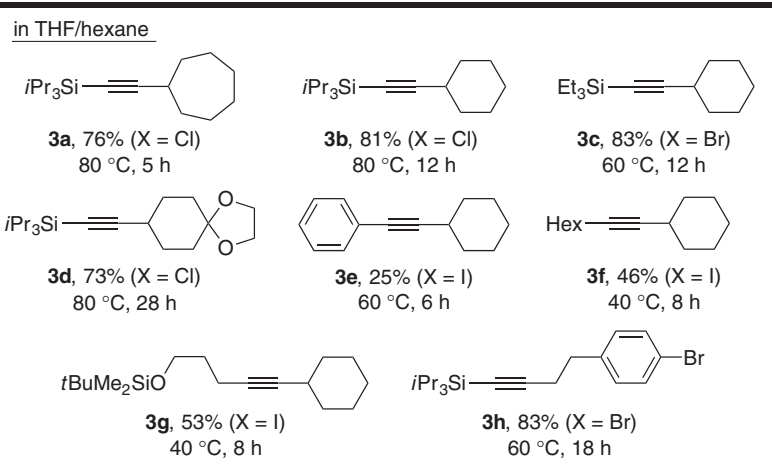

$$
\text { in toluene }
$$
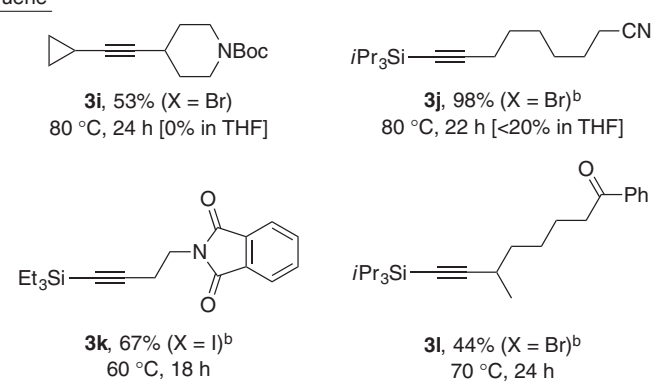

a Reactions were carried out at the $0.50 \mathrm{mmol}$ scale. Yields of isolated products are reported. ${ }^{\mathrm{b}} 10 \mathrm{~mol} \%$ of $\left[\mathrm{FeCl}_{2}(\mathrm{SciOPP})\right]$ and 2 equivalents of $\mathbf{2}$ were used.

yield, and showed diminished selectivity (Table 1, Entry 3). DPPBz, ${ }^{7 \mathrm{e}-7 \mathrm{~g}}$ DPPE, ${ }^{11}$ and NMP, ${ }^{5 \mathrm{~h}, 7 \mathrm{a}}$ which are well-recognized modifiers for iron-catalyzed cross-coupling reactions, were totally ineffective (Table 1, Entries 4-6). Other alkynylborates derived from $\mathrm{B}(\mathrm{O} i \mathrm{Pr})_{3}{ }^{2 \mathrm{e}}$ and $9-\mathrm{MeO}-9-\mathrm{BBN}^{2 \mathrm{~b}, 2 \mathrm{c}}$ did not take part in the cross-coupling reaction (Table 1, Entries 7 and 8).

We next investigated the scope of the current protocol and found that it was applicable to various combinations of alkyl halides and alkynylborates (Table 2). (Triethylsilyl)ethynylborate also showed good reactivity toward bromocyclohexane, affording the target alkyne $\mathbf{3 c}$ in $83 \%$ yield. A cyclic acetal was tolerant to the reaction conditions to give $3 \mathbf{d}$ in $73 \%$ yield. (Phenyl)ethynylborate reacted to give 3e albeit in a low yield. Reactions of primary alkyl-substituted alkynylborates were also found to be sluggish, yet they reacted with primary or secondary alkyl iodides to afford the coupling products $\mathbf{3 f}$ and $\mathbf{3 g}$ in moderate yields. The reaction of 1-bromo-4-(2-bromoethyl)benzene with 2 occurred selectively at the $\mathrm{C}_{\mathrm{sp}^{3}}-\mathrm{Br}$ position to afford 3h in $83 \%$ yield, leaving the $\mathrm{C}_{\mathrm{sp}^{2}}-\mathrm{Br}$ bond completely intact. In the case of sterically small alkyne substituents, such as the (cyclopropyl)ethynyl group, the target product $\mathbf{3 i}$ was not obtained, even with refluxing in THF. We assumed that even the borate reagent, which possesses a small substituent on the alkyne carbon, could form inert iron intermediates such as ferrate complexes in a polar solvent like THF (Table 2 and

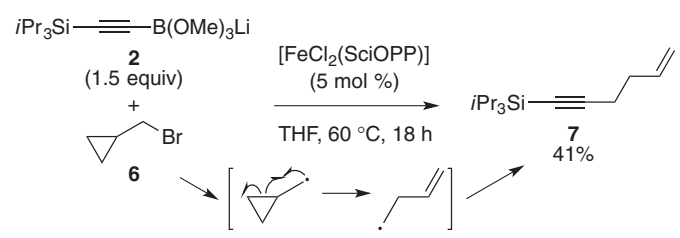

Scheme 2. Radical probe experiment.

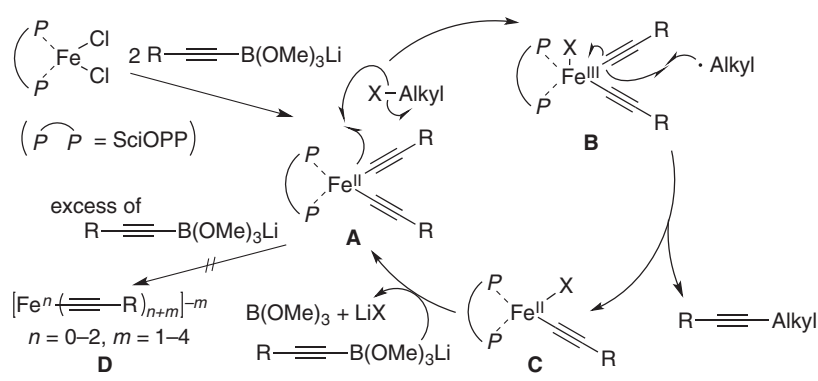

Figure 1. A plausible catalytic cycle for the current reaction.

Figure 1). We thus replaced the THF solvent with toluene, and found that the coupling reaction worked well even with the sterically unhindered alkynylborate and obtained the cyclopropylethynylated compound $\mathbf{3 i}$ in $53 \%$ yield. Toluene solvent was effective also for the alkyl halides possessing a reactive functional group, such as nitrile, imide, and ketone (3j-3l). We reasoned that the low polarity of the toluene solvent prevented the side reactions on these functional groups with alkynyl iron species. $^{12}$

To investigate the reaction mechanism, we conducted the reaction of (bromomethyl)cyclopropane (6) with 2 (Scheme 2). The linear 1,5-enyne 7 formed in $41 \%$ yield selectively, suggesting that the reaction proceeds via formation of an alkyl radical species. Based on the experimental observations described above, and accumulated knowledge of iron-catalyzed cross-coupling reactions, ${ }^{5 \mathrm{~g}, 7,8}$ we present a possible catalytic cycle, shown in Figure 1. We assume that the dialkynyl-ironSciOPP intermediate $\mathbf{A}$ is responsible for the selective cross coupling through the putative iron intermediates $\mathbf{B}$ and $\mathbf{C}$, whilst the ferrate complexes $\mathbf{D}$ that can form in the presence of an excess of the Grignard reagent ${ }^{13}$ do not possess sufficient reactivity towards the alkyl halides. Presumably, the steric bulk of SciOPP prevents the formation of the undesired ferrate formation.

In summary, we have developed the iron-catalyzed SuzukiMiyaura coupling of unactivated alkyl halides with alkynylborate reagents. The reaction has synthetic advantages over more traditional methods, such as its simple operation, its applicability to a broad scope of alkyl halides including chlorides, and its high functional group compatibility. At present, details of the reaction mechanism are unclear, and evaluation of the postulated catalytic cycle is imperative. Further efforts on the elucidation of the mechanism are currently underway.

This research was funded in part by a grant from the Japan Society for the Promotion of Science (JSPS) through the "Funding Program for Next Generation World-Leading Researchers (NEXT Program)," initiated by the Council for 
Science and Technology Policy (CSTP), and also supported by the Japan Science and Technology Agency (JST), and the Core Research for Evolutional Science and Technology (CREST 1102545) Program. This research is also supported in part by the MEXT program "Elements Strategy Initiative to Form Core Research Center." We thank Prof. Dr. Katsuhiro Isozaki (Kyoto University) for the FT-MS analyses.

Supporting Information is available electronically on J-STAGE.

\section{References and Notes}

$\dagger$ Present address: School of Science and Technology, Department of Chemistry, Kwansei Gakuin University, 2-1 Gakuen, Sanda, Hyogo 669-1337

1 a) Boronic Acids: Preparation and Applications in Organic Synthesis, Medicine and Materials, 2nd ed., ed. by D. G. Hall, Wiley-VCH, Weinheim, 2011. doi:10.1002/9783527639328. b) N. Miyaura, A. Suzuki, Chem. Rev. 1995, 95, 2457. c) N. Miyaura, in Topics in Current Chemistry, Springer, 2002, Vol. 219, p. 11. doi:10.1007/3-540-45313-X_2. d) G. A. Molander, N. Ellis, Acc. Chem. Res. 2007, 40, 275. e) A. Suzuki, Angew. Chem., Int. Ed. 2011, 50, 6722. f) A. J. J. Lennox, G. C. Lloyd-Jones, Chem. Soc. Rev. 2014, 43, 412.

2 a) E. Negishi, in Aspects of Mechanism and Organometallic Chemistry, ed. by J. H. Brewster, Plenum, New York, 1978, p. 285. doi:10.1007/978-1-4684-3393-7_12. b) J. A. Soderquist, K. Matos, A. Rane, J. Ramos, Tetrahedron Lett. 1995, 36, 2401. c) A. Fürstner, G. Seidel, Tetrahedron 1995, 51, 11165. d) A.-S. Castanet, F. Colobert, T. Schlama, Org. Lett. 2000, 2, 3559. e) C. H. Oh, S. H. Jung, Tetrahedron Lett. 2000, 41, 8513. f) G. A. Molander, B. W. Katona, F. Machrouhi, J. Org. Chem. 2002, 67, 8416. g) F. Colobert, A.-S. Castanet, O. Abillard, Eur. J. Org. Chem. 2005, 3334. h) G. Hernández Torres, S. Choppin, F. Colobert, Eur. J. Org. Chem. 2006, 1450. i) G. R. Cumming, G. Bernardinelli, E. P. Kündig, Chem.-Asian J. 2006, 1, 459.

3 a) A. Fürstner, K. Nikolakis, Liebigs Ann. 1996, 2107. b) A. Fürstner, L. Turet, Angew. Chem., Int. Ed. 2005, 44, 3462. c) A. Fürstner, J. W. J. Kennedy, Chem.-Eur. J. 2006, 12, 7398. d) A. Fürstner, D. De Souza, L. Turet, M. D. B. Fenster, L. ParraRapado, C. Wirtz, R. Mynott, C. W. Lehmann, Chem.-Eur. J. 2007, 13, 115. e) H. Park, H. Kim, J. Hong, Org. Lett. 2011, 13, 3742. f) G. Seidel, A. Fürstner, Chem. Commun. 2012, 48, 2055.

4 Sonogashira coupling reactions of unactivated alkyl halides using copper cocatalyst were reported. Pd catalyst: a) M. Eckhardt, G. C. Fu, J. Am. Chem. Soc. 2003, 125, 13642. b) G. Altenhoff, S. Würtz, F. Glorius, Tetrahedron Lett. 2006, 47, 2925. Ni catalyst: c) O. Vechorkin, D. Barmaz, V. Proust, X. Hu, J. Am. Chem. Soc. 2009, 131, 12078. d) J. Yi, X. Lu, Y.-Y. Sun, B. Xiao, L. Liu, Angew. Chem., Int. Ed. 2013, 52, 12409.

5 Sonogashira-type coupling reactions of unactivated alkyl halides with Grignard reagents were reported. Pd catalyst: a) L.-M. Yang, L.-F. Huang, T.-Y. Luh, Org. Lett. 2004, 6, 1461. Ni catalyst: b) O. Vechorkin, A. Godinat, R. Scopelliti, X. Hu, Angew. Chem., Int. Ed. 2011, 50, 11777. Co catalyst: c) A. Kuno, N. Saito, T. Kamachi, S. Okamoto, Tetrahedron Lett. 2006, 47, 2591. d) H. Ohmiya, H. Yorimitsu, K. Oshima, Org. Lett. 2006, 8, 3093. e) H. Someya, H. Ohmiya, H. Yorimitsu, K. Oshima, Org. Lett. 2007, 9 , 1565. f) H. Someya, H. Ohmiya, H. Yorimitsu, K. Oshima, Tetrahedron 2007, 63, 8609. Fe catalyst: g) T. Hatakeyama, Y. Okada, Y. Yoshimoto, M. Nakamura, Angew. Chem., Int. Ed. 2011, 50, 10973. h) C. W. Cheung, P. Ren, X. Hu, Org. Lett. 2014, 16 , 2566.

6 SciOPP is the abbreviation for spin-controlled intended ortho- phenylene-bisphosphine, which is commercially available from Wako Pure Chemical Industries, Ltd.

7 Selected examples of the iron-catalyzed cross-coupling reaction of alkyl halides with aryl Grignard reagents: a) A. Fürstner, R. Martin, H. Krause, G. Seidel, R. Goddard, C. W. Lehmann, J. Am. Chem. Soc. 2008, 130, 8773. b) T. Hatakeyama, Y. Fujiwara, Y. Okada, T. Itoh, T. Hashimoto, S. Kawamura, K. Ogata, H. Takaya, M. Nakamura, Chem. Lett. 2011, 40, 1030. c) C.-L. Sun, H. Krause, A. Fürstner, Adv. Synth. Catal. 2014, 356, 1281. With arylzinc reagents: d) M. Nakamura, S. Ito, K. Matsuo, E. Nakamura, Synlett 2005, 1794. e) R. B. Bedford, M. Huwe, M. C. Wilkinson, Chem. Commun. 2009, 600. f) T. Hatakeyama, Y. Kondo, Y. Fujiwara, H. Takaya, S. Ito, E. Nakamura, M. Nakamura, Chem. Commun. 2009, 1216. g) C. J. Adams, R. B. Bedford, E. Carter, N. J. Gower, M. F. Haddow, J. N. Harvey, M. Huwe, M. Á. Cartes, S. M. Mansell, C. Mendoza, D. M. Murphy, E. C. Neeve, J. Nunn, J. Am. Chem. Soc. 2012, 134, 10333.

8 We previously reported the iron-catalyzed Suzuki-Miyaura coupling of alkyl halides. With aryl borate reagents: a) T. Hatakeyama, T. Hashimoto, Y. Kondo, Y. Fujiwara, H. Seike, H. Takaya, Y. Tamada, T. Ono, M. Nakamura, J. Am. Chem. Soc. 2010, 132, 10674. With alkenyl borate reagents: b) T. Hashimoto, T. Hatakeyama, M. Nakamura, J. Org. Chem. 2012, 77, 1168. With alkyl borate reagents: c) T. Hatakeyama, T. Hashimoto, K. K. A. D. S. Kathriarachchi, T. Zenmyo, H. Seike, M. Nakamura, Angew. Chem., Int. Ed. 2012, 51, 8834.

9 The ${ }^{11}$ B NMR spectrum for the mixture of lithium triisopropyl ethynylide and a small excess of trimethyl borate showed four peaks in the range of 19 to $-4 \mathrm{ppm}$. These peaks are attributed to trimethyl borate (18.7 ppm as a minor peak), 2 (3.4 ppm as a dominant peak), lithium tetramethoxoborate $(1.7 \mathrm{ppm}$ as a minor peak), and lithium dimethoxodialkynylborate $(-3.7 \mathrm{ppm}$ as a minor peak) relative to $\mathrm{BF}_{3} \cdot \mathrm{Et}_{2} \mathrm{O}$ as an external standard. We assume that these boron compounds can form through a disproportionation reaction. See also Refs. $2 \mathrm{~g}$ and $3 \mathrm{a}$.

10 Ligand, additive, and boron reagent structure abbreviations:

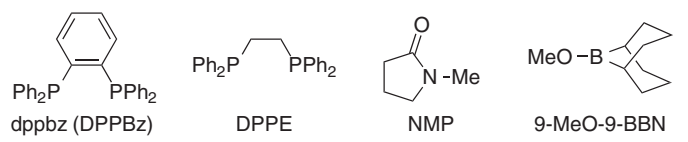

11 Bedford and his co-workers recently demonstrated that simple bisphosphines, such as dppe, also work as an effective ligand on the iron-catalyzed Suzuki-Miyaura coupling of alkyl halides with aryl borate reagents: R. B. Bedford, P. B. Brenner, E. Carter, T. W. Carvell, P. M. Cogswell, T. Gallagher, J. N. Harvey, D. M. Murphy, E. C. Neeve, J. Nunn, D. R. Pye, Chem.-Eur. J. 2014, 20, 7935 .

12 Lithium alkynyl trimethylborates react with aldehydes but not with nitrile, ester, and ketone. See: I. N. Francesco, A. Renier, A. Wagner, F. Colobert, Tetrahedron Lett. 2010, 51, 1386.

13 Alkynylferrate complexes were previously reported. a) R. Nast, F. Urban, Z. Anorg. Allg. Chem. 1956, 287, 17. b) L. A. Berben, J. R. Long, Inorg. Chem. 2005, 44, 8459. c) G. M. Yee, K. Kowolik, S. Manabe, J. C. Fettinger, L. A. Berben, Chem. Commun. 2011, 47, 11680. An organoiron(II)-SciOPP complex is proven as a reactive intermediate in iron-catalyzed cross couplings of alkyl halides with mesityl Grignard reagent. d) H. Takaya, S. Nakajima, N. Nakagawa, K. Isozaki, T. Iwamoto, R. Imayoshi, N. J. Gower, L. Adak, T. Hatakeyama, T. Honma, M. Takagaki, Y. Sunada, H. Nagashima, D. Hashizume, O. Takahashi, M. Nakamura, Bull. Chem. Soc. Jpn. in press. doi:10.1246/bcsj.20140376. e) S. L. Daifuku, M. H. Al-Afyouni, B. E. R. Snyder, J. L. Kneebone, M. L. Neidig, J. Am. Chem. Soc. 2014, 136, 9132. 